\title{
Prenatal diagnosis and management of hypoplastic left heart syndrome: Single center results
}

\section{Yunus Emre PURUT \\ D Gürcan TÜRKYILMAZ}

Department of Gynecology and Obstetrics, Van Training and Research Hospital, Van, Turkey

\section{ORCID ID}

YEP : 0000-0001-5779-3847

GT : 0000-0002-5514-0233

\begin{abstract}
Objective: Hypoplastic left heart syndrome (HLHS) is the most common reason for neonatal deaths among congenital heart defects. Numerous studies showed that prenatal diagnosis improves prognosis. We aimed to review the prenatal assessment of associated extracardiac anomalies, postnatal outcomes, and surgical management in cases of HLHS that were detected in our center.
\end{abstract}

Material and Methods: The records of patients diagnosed with HLHS evaluated between March 2017 and April 2020. A detailed anatomy scan was performed, and karyotype analysis was recommended to all patients. Due to poor perinatal prognosis, termination of pregnancy (TOP) was offered an option to families. Serial ultrasonographic examinations every 2-4 weeks. Postnatal echocardiography was performed, and the prenatal diagnosis was confirmed in all offspring. Surgical outcomes were recorded.

Results: Sixteen patients were recruited in our study. The mean gestational age at diagnosis was $20.2 \pm 5.1$ weeks. About $68.7 \%$ of cases were defined as classical type HLHS, and the remaining $31.3 \%$ were determined as variant type HLHS. TOP was performed in 9 (56.7\%) patients. The mean follow-up interval was $16.4 \pm 4.7$ months. Urge septostomy was performed in $2(28.5 \%)$ cases after birth due to foramen ovale restriction. Three (42.8\%) cases died before the first operation. Norwood procedure was performed in $4(57.1 \%)$ cases. Two cases died after this operation. Glenn shunt and Fontan procedure were performed in the remaining two offspring. The total survival rate was $28.5 \%$.

Conclusion: HLHS has high perinatal morbidity and mortality. Prenatal diagnosis allows the family for the fate of pregnancy and planned delivery in a tertiary center.

Keywords: Echocardiography, heart, mortality, prenatal.

Cite this article as: Purut YE, Türkyılmaz G. Prenatal diagnosis and management of hypoplastic left heart syndrome: Single center results. Zeynep Kamil Med J 2021;52(1):16-20.

Received: November 13, 2020 Accepted: December 01, 2020 Online: April 06, 2021

Correspondence: Gürcan TÜRKYILMAZ, MD. Van Eğitim ve Araştırma Hastanesi, Kadın Hastalıkları ve Doğum Kliniği, Van, Turkey. Tel: +90 5543102803 e-mail: gurcanturkyilmaz@gmail.com

(c) Copyright 2021 by Zeynep Kamil Medical Journal - Available online at www.zeynepkamilmedj.com 


\section{INTRODUCTION}

Hypoplastic left heart syndrome (HLHS) is a complex cardiac anomaly that causes systemic perfusion failure by the left ventricle. Anatomically, various pathologies may lead to HLHS. Due to atresia of the mitral valve and aortic valve, the left ventricular cavity may completely absent, or the hypoplastic development of the aortic and mitral valve may allow the evolution of a small left ventricular cavity. Ascending aorta and aortic arch hypoplasia or aortic coarctation are associated with HLHS. ${ }^{[1]}$

HLHS has a frequency of 2-3/10,000 live births and constitutes $3-4 \%$ of all cardiac anomalies. ${ }^{[2,3]}$ It is $50 \%$ more frequently in male babies than girls. ${ }^{[4]}$ Although it is a rare cardiac anomaly, HLHS solely is responsible for $40-50 \%$ of cardiac deaths. ${ }^{[5]}$ Non-cardiac anomalies are associated with $5-30 \%$ of cases, and the most common anomalies are the central nervous system, gastrointestinal system, and renal system malformations. Chromosomal anomalies are detected in 5-10\% of cases, and trisomy $13-18$ and monosomy $X$ (Turner syndrome) are most common aneuploidies. ${ }^{[6]}$ Rarely, it may be associated with microdeletion syndromes such as WilliamsBeuren syndrome (7q11.23 deletion) and DiGeorge syndrome (22q11.1 deletion).

However, HLHS constitutes a small group of all cardiac anomalies; it is one of the most common cardiac anomalies in the prenatal period. Unlike conotruncal anomalies, an abnormal four-chamber view of the fetal heart seems to be the main factor facilitating the diagnosis. The most common finding in prenatal ultrasonography is the absence of the left ventricle in four-chamber view or the presence of a hypoplastic, hypocontractile, and hyperechogenic left ventricle. Numerous studies indicated that prenatal diagnosis had improved neonatal outcomes. ${ }^{[7]}$

In this study, we aimed to evaluate the prenatal findings and postnatal outcomes of the cases diagnosed prenatally with HLHS in our clinic.

\section{MATERIAL AND METHODS}

Our study was carried out in the Perinatology Department of Van Training and Research Hospital between March 2017 and April 2020. Diagnosis of HLHS was achieved in those findings: (1) In the apical four-chamber view of the heart, the left ventricle is absent, or there was a small and hyperechogenic left ventricle with reduced contractility. (2) The apex of the heart was formed by the right ventricle. (3) No transition from the mitral valve to the left ventricle in color Doppler evaluation. (4) The foramen ovale flap was placed by opening from right to left instead of from left to right (Fig. 1). Furthermore, the absence of the aorta in the three-vessel trachea plan and the aortic arch filling with a reverse flow from the ductal arch in the color Doppler examination confirmed the diagnosis (Fig. 2). Cases with no visible left ventricle in the apical four-chamber examination were defined as classical type HLHS. In contrast, cases with a hyperechogenic and hypocontractile left ventricle were determined as variant type HLHS due to stenosis of the aortic and mitral valve. In all cases, prenatal diagnosis was confirmed with a consensus of perinatologist and pediatric cardiology specialist. After the diagnosis, a detailed fetal anatomic evaluation was performed in all cases to rule out extra-

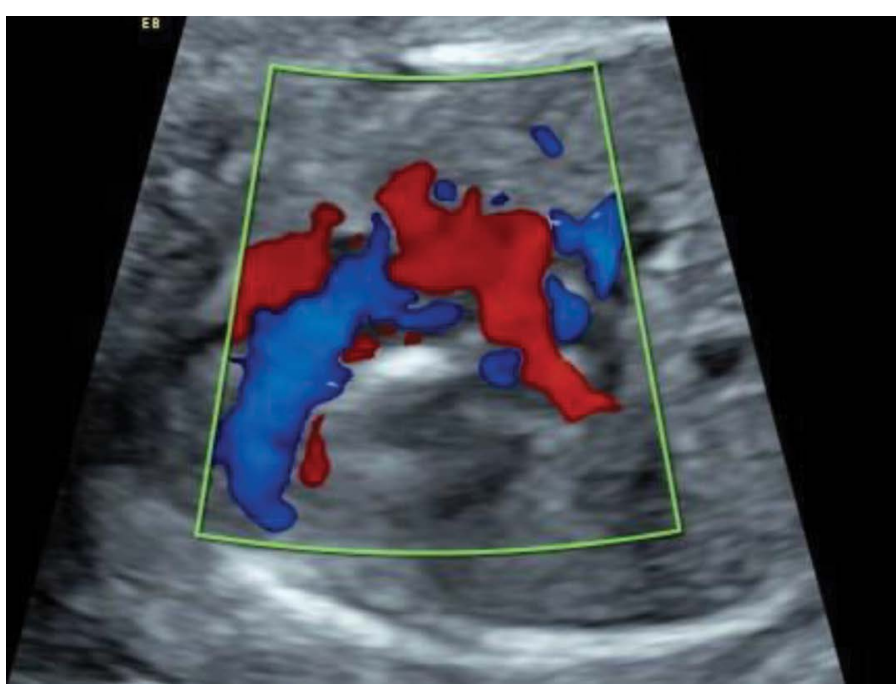

Figure 1: There is no filling of the left ventricle in color Doppler examination and left ventricle hypoplasia is observed in 26 weeks of gestation.

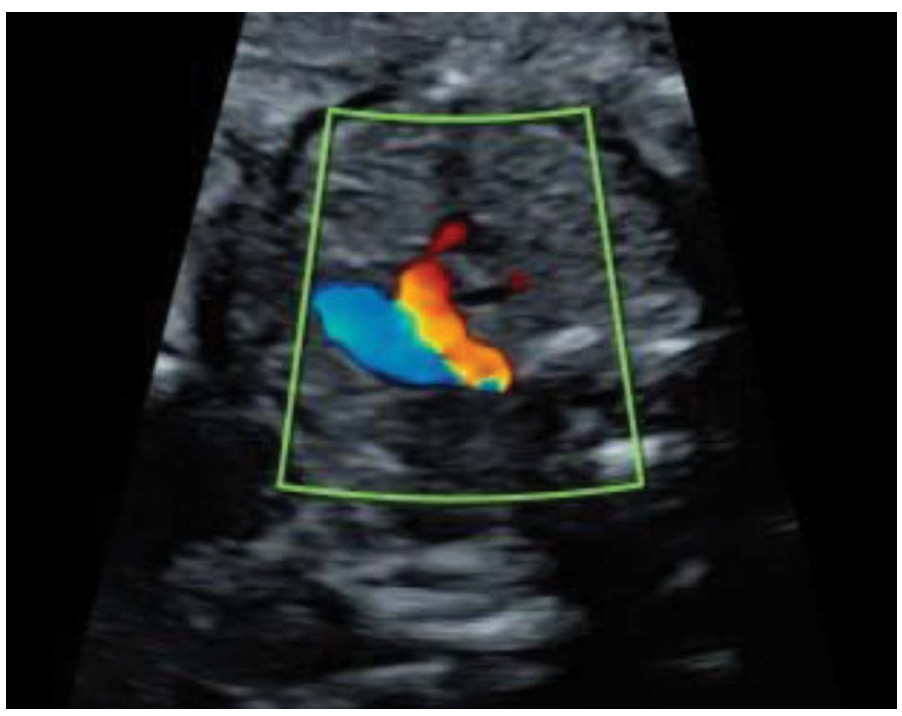

Figure 2: Reverse flow in the aortic arch in three-vessel trachea view in a 19-week fetus.

cardiac anomalies, and karyotype analysis was recommended. Due to poor neonatal prognosis, the option of termination of pregnancy (TOP) was offered to families in all cases. Serial follow-up was performed every 2-4 weeks in cases wishing to continue the pregnancy. All women were delivered in tertiary care centers. Echocardiography was performed in all cases after birth, and the diagnosis of HLHS was confirmed. Long-term surgical procedures and survival rates of the cases were recorded. Statistical analysis was performed using SPSS version 24 (Statistical Package for the Social Sciences, IL, USA). Results were expressed as mean and standard deviation.

\section{RESULTS}

We recruited 16 cases during the study period. Mean maternal age was $25.6 \pm 5.2$ years, and mean gestational age at diagnosis was $20.2 \pm 5.1$ weeks. About $68.7 \%$ of fetuses were defined as classi- 
Table 1: Prenatal features of 16 cases

\begin{tabular}{lc} 
Variable & $\mathbf{n = 1 6}(\%)$ \\
\hline Maternal age (years) & $25.6 \pm 5.2$ \\
Gestational age at diagnosis (weeks) & $20.2 \pm 5.1$ \\
HLHS type & \\
$\quad$ Classical & $11(68.7)$ \\
$\quad$ Variant type & $5(31.3)$ \\
Nuchal translucency (mm) & $3.2 \pm 1.1$ \\
Karyotype analysis & $8(50)$ \\
Extracardiac anomaly & $2(12.5)$ \\
Foramen ovale restriction & $2(12.5)$ \\
TOP & $9(56.2)$
\end{tabular}

TOP: Termination of pregnancy.

cal type HLHS and $31.3 \%$ as variant type HLHS. The mean nuchal translucency measurement of cases was $3.2 \pm 1.1 \mathrm{~mm}$ in the first trimester. Karyotype analysis was performed in 8 (50\%) cases, and normal karyotype was found in all patients. An extracardiac anomaly was observed in 2 cases (12.5\%), including 1 case with unilateral renal agenesis and 1 case with unilateral pes equinovarus. Foramen ovale restriction was revealed in the prenatal period in (31.3\%) of the fetuses. TOP was performed in $9(56.7 \%)$ cases. The mean gestational age at birth was $37.4 \pm 2.1$. The mean birth weight was $2530 \pm 355 \mathrm{~g}$ of $7(43.7 \%)$ cases born alive. Two (28.5\%) cases were delivered vaginally, and $5(71.5 \%)$ cases were delivered by cesarean section. Four (57.1\%) cases were female, and 3 (42.9\%) cases were male. The mean follow-up period was $16.4 \pm 4.7$ months, and the mean length of stay in the neonatal intensive care unit was $86 \pm 23$ days. Foramen ovale restriction was detected in $2(28.5 \%)$ cases after birth, and emergency septostomy was performed in those babies. Three (42.8\%) cases died before the first operation. Two of these three cases required emergency septostomy after delivery due to prenatal foramen ovale restriction. Norwood procedure was performed in four babies. Two cases died after this operation. One of those two patients died on the $1^{\text {st }}$ post-operative day, and the other died 5 days after the Norwood procedure. Glenn shunt and Fontan procedure were performed in the remaining two cases. Overall survival calculated as $28.5 \%$. Prenatal features and outcome of cases were demonstrated in Table 1 and Table 2.

\section{DISCUSSION}

Recently, progressions on ultrasonography technology and amelioration in physicians skills and experience have improved prenatal diagnosis of fetal anomalies. While cardiac anomalies are detected in 5-8/1000 of all fetuses, some cardiac anomalies remain undiagnosed in the prenatal period. Morris et al. ${ }^{[8]}$ studied 3.4 million birth records in Texas between 1997 and 2007 years and had found the prenatal diagnosis rate $39 \%$ for in 558 isolated HLHS babies. Between 2002 and 2012 years, van Velzen et al. ${ }^{[9]}$ had investigated the
Table 2: Outcome of seven cases who survived in neonatal period

\begin{tabular}{lc} 
Variable & $\mathbf{n = 1 7}(\%)$ \\
\hline Gestational age at birth (weeks) & $37.4 \pm 2.1$ \\
Birth weight (grams) & $2530 \pm 355$ \\
Route of delivery & \\
$\quad$ Vaginal & $2(28.5)$ \\
$\quad$ Cesarean & $5(71.4)$ \\
Sex & \\
$\quad$ Male & $4(57.1)$ \\
$\quad$ Female & $3(42.9)$ \\
Foramen ovale restriction & $2(28.5)$ \\
Follow-up period (months) & $16.4 \pm 4.7$ \\
NICU stay (day) & $86 \pm 23$ \\
Neonatal death & $3(42.8)$ \\
Norwood procedure & $4(57.1)$ \\
Glenn shunt & $2(28.5)$ \\
Fontan procedure & $2(28.5)$ \\
Overall survival & $2(28.5)$
\end{tabular}

NICU: Neonatal intensive care unit.

results of the standard anomaly scanning program in the Netherlands and found the rate $59.6 \%$ in prenatal diagnosis for cardiac anomalies. HLHS is the most diagnosed anomaly, and $94 \%$ of all fetuses with HLHS were diagnosed correctly.

Getting a prenatal diagnosis of HLHS helps provide the family with detailed counseling regarding postnatal results and treatment methods. Because HLHS treatment can comprise multiple operations and mortality rates are high, some families choose TOP. In their study, Liu et al., ${ }^{[10]}$ including 381 patients diagnosed with a single ventricle, showed that percentage of 16 families selected TOP. The most crucial factor that affects the TOP decision is being diagnosed before 20 pregnancy weeks. Beroukhim et al. ${ }^{[11]}$ showed $32 \%$ TOP rate for the study, including 312 fetuses with a single ventricle. In our study, 9 of 16 cases selected TOP (56.2\%). High TOP rates in our study can be explained by the fact that HLHS operation carries out only in limited centers in our country, and mortality rates are still high compared to developed countries.

Delivery of HLHS diagnosed fetuses must be done in tertiary centers experienced in this field. Morris et al. ${ }^{[8]}$ have found $21 \%$ perinatal mortality. The baby delivery center was $<10$ min distance to the cardiac surgery center, $25.1 \%$ perinatal mortality with distance $10-90$ $\mathrm{min}$, and $39.6 \%$ with distance more than $90 \mathrm{~min}$, respectively. Thakur et al. ${ }^{[12]}$ published a meta-analysis that included 228 prenatal, 381 postnatal diagnosed patients and showed that neonatal death rates among babies were $11 \%$ and $17 \%$ for prenatally and postnatally diagnosed babies. Otherwise, pre-operative acidosis, inotropic agent need, and mortality rate after Stage-1 surgery were found significantly to be lower in the prenatally diagnosed group. Our study delivery 
of all cases prenatally diagnosed has been ensured to carry out in tertiary centers under elective conditions.

About $30 \%$ of babies with HLHS are accompanied by genetic or/ and extracardiac anomalies. Genetic disorders such as Trisomy 18, Turner syndrome, and DiGeorge (22q11.21-2 deletion) and Jacobson syndrome (11 q deletion) are related to HLHS. Hinton et al. ${ }^{[13,14]}$ showed an association between chromosomal mutations 10q22 and $6 q 23$ with HLHS, and they have found that HLHS risk for subsequent pregnancy was $8.1 \%$. We also suggested karyotype analyze in all cases, and results were found normal for all eight patients.

Newborns diagnosed with HLHS are asymptomatic if there is no restriction of foramen ovale during the prenatal period, but 24-48 $\mathrm{h}$ after delivery, ductus arteriosus shuts down, and systemic hypoperfusion, hypotension, and metabolic acidosis occur. If urgent medical care cannot be given, death will be inevitable. HLHS has the most complicated surgery treatment among all cardiac anomalies, and incompatible with life if it remains untreated. However, in recent years, survival rates have increased in parallel with amelioration in surgical techniques and improved intensive care units. HLHS treatment includes the stepwise surgical procedure. The first operation is the Norwood procedure that is done 2 or 3 weeks after birth. The two-way Glenn shunt is made after $2-6$ months after delivery. The last stage is the Fontan operation and is held when the patient is between 2 and 5 years old. After HLHS surgical treatment, survival rates between 3 and 6 years old are $60-70 \% .{ }^{[15,16]}$ High mortality surgical intervention is Norwood operation, and if this operation is successful, the longterm survival rate can reach $90 \% .{ }^{[17]}$ A study investigating 26-year birth statistics in Atlanta between 1979 and 1984 has found $0 \%$ neonatal survival rate of HLHS patients. However, between 1999 and 2005 years, this rate was $45 \% .{ }^{[18]}$ In our study, the long-term survival rate was $28.5 \%$. This ratio is below the rates of developed countries.

Among the patients operated because of single ventricle physiology, long-term studies revealed a high risk of neurodevelopmental retardation. In the single ventricle reconstruction trial study, where 321 children underwent the stepwise surgical treatment in the case of HLHS, the primary surveillance time was $14.3 \pm 1.1$ months. Mean Bayley score and psychomotor development score in operated patients were found significantly low than the same in the healthy control group. ${ }^{[19]}$ Mahle et al. ${ }^{[20]}$ revealed considerably lower neurodevelopmental test scores in over 8-year-old children who underwent HLHS operation than in the control group.

In parallel with the improvements in fetal surgical techniques, prenatal treatment methods have been tried invariant type HLHS cases. In a few specialized centers, eligible cases with critical aortic stenosis and sufficient left ventricle volume undergo fetal treatment procedures. In their 100 case series between 2000 and 2013 years in fetuses who underwent fetal surgery, Freud et al. ${ }^{[21]}$ showed fetal aortic valvuloplasty bettering the newborn long-term consequences.

\section{CONCLUSION}

HSKS is rare, but the most common cause of death due to cardiac anomalies in the neonatal period. Diagnosis in the prenatal period enables delivery to be performed at a tertiary center and improves long-term results.

\section{Statement}

Peer-review: Externally peer-reviewed.

Author Contributions: Concept - GT, YEP; Design - GT, YEP; Supervision - GT, YEP; Resource - GT, YEP; Materials - GT, YEP; Data Collection and/ or Processing - GT, YEP; Analysis and/or Interpretation - GT, YEP; Literature Search - GT, YEP; Writing - GT, YEP; Critical Reviews - GT, YEP.

Conflict of Interest: The authors have no conflict of interest to declare.

Financial Disclosure: The authors declared that this study has received no financial support.

\section{REFERENCES}

1. Rychik J. Hypoplastic left heart syndrome: From in utero diagnosis to school age. Semin Fetal Neonatal Med 2005; 10(6): 553-66.

2. Gordon BM, Rodriguez S, Lee M, Chang RK. Decreasing number of deaths of infants with hypoplastic left heart syndrome. J Pediatr 2008; 153(3): 354-8

3. Karamlou T, Diggs BS, Ungerleider RM, Welke KF. Evolution of treatment options and outcomes for hypoplastic left heart syndrome over an 18-year period. J Thorac Cardiovasc Surg 2010; 139(1): 119-26; discussion 126-7.

4. Fixler DE, Nembhard WN, Salemi JL, Ethen MK, Canfield MA. Mortality in first 5 years in infants with functional single ventricle born in Texas, 1996 to 2003. Circulation 2010; 121(5): 644-50.

5. Reller MD, Strickland MJ, Riehle-Colarusso T, Mahle WT, Correa A. Prevalence of congenital heart defects in metropolitan Atlanta, 19982005. J Pediatr 2008; 153(6): 807-13.

6. Natowicz M, Chatten J, Clancy R, Conard K, Glauser T, Huff D, et al. Genetic disorders and major extracardiac anomalies associated with the hypoplastic left heart syndrome. Pediatrics 1988; 82(5): 698-706.

7. Morris SA, Ethen MK, Penny DJ, Canfield MA, Minard CG, Fixler DE, et al. Prenatal diagnosis, birth location, surgical center, and neonatal mortality in infants with hypoplastic left heart syndrome. Circulation 2014; 129(3): 285-92.

8. Morris SA, Ethen MK, Penny DJ, Canfield MA, Minard CG, Fixler DE, et al. Prenatal diagnosis, birth location, surgical center, and neonatal mortality in infants with hypoplastic left heart syndrome. Circulation 2014; 129(3): 285-92.

9. van Velzen $\mathrm{CL}$, Clur SA, Rijlaarsdam ME, Bax CJ, Pajkrt E, Heymans $\mathrm{MW}$, et al. Prenatal detection of congenital heart disease--results of a national screening programme. BJOG 2016; 123(3): 400-7.

10. Liu MY, Zielonka B, Snarr BS, Zhang X, Gaynor JW, Rychik J. Longitudinal assessment of outcome from prenatal diagnosis through Fontan operation for over 500 fetuses with single ventricle-type congenital heart disease: The Philadelphia fetus-to-Fontan cohort study. J Am Heart Assoc 2018; 7(19): e009145.

11. Beroukhim RS, Gauvreau K, Benavidez OJ, Baird CW, LaFranchi T, Tworetzky W. Perinatal outcome after prenatal diagnosis of single-ventricle cardiac defects. Ultrasound Obstet Gynecol 2015; 45(6): 657-63.

12. Thakur V, Munk N, Mertens L, Nield LE. Does prenatal diagnosis of hypoplastic left heart syndrome make a difference? A systematic review. Prenat Diagn 2016; 36(9): 854-63.

13. Benson DW, Martin LJ, Lo CW. Genetics of hypoplastic left heart syndrome. J Pediatr 2016; 173: 25-31.

14. Hinton RB, Martin LJ, Rame-Gowda S, Tabangin ME, Cripe LH, Benson DW. Hypoplastic left heart syndrome links to chromosomes $10 \mathrm{q}$ and 
$6 \mathrm{q}$ and is genetically related to bicuspid aortic valve. J Am Coll Cardiol 2009; 53(12): 1065-71.

15. Scheurer MA, Salvin JW, Vida VL, Fynn-Thompson F, Bacha EA, Pigula $F A$, et al. Survival and clinical course at Fontan after stage one palliation with either a modified Blalock-Taussig shunt or a right ventricle to pulmonary artery conduit. J Am Coll Cardiol 2008; 52(1): 52-9.

16. Ballweg JA, Dominguez TE, Ravishankar C, Gaynor JW, Nicolson SC, Spray TL, et al. A contemporary comparison of the effect of shunt type in hypoplastic left heart syndrome on the hemodynamics and outcome at Fontan completion. J Thorac Cardiovasc Surg 2010; 140(3): 537-44.

17. Siffel C, Riehle-Colarusso T, Oster ME, Correa A. Survival of Children with hypoplastic left heart syndrome. Pediatrics 2015; 136(4): e864.

18. Alsoufi B, Mori M, Gillespie S, Schlosser B, Slesnick T, Kogon B, et al. Impact of patient characteristics and anatomy on results of Norwood operation for hypoplastic left heart syndrome. Ann Thorac Surg 2015; 100(2): 591-8.

19. Newburger JW, Sleeper LA, Bellinger DC, Goldberg CS, Tabbutt S, Lu $M$, et al. Early developmental outcome in children with hypoplastic left heart syndrome and related anomalies: The single ventricle reconstruction trial. Circulation 2012; 125(17): 2081-91.

20. Mahle WT, Visconti KJ, Freier MC, Kanne SM, Hamilton WG, Sharkey $\mathrm{AM}$, et al. Relationship of surgical approach to neurodevelopmental outcomes in hypoplastic left heart syndrome. Pediatrics 2006; 117(1): e90-7.

21. Freud LR, McElhinney DB, Marshall AC, Marx GR, Friedman KG, del Nido PJ, et al. Fetal aortic valvuloplasty for evolving hypoplastic left heart syndrome: Postnatal outcomes of the first 100 patients. Circulation 2014; 130(8): 638-45. 